\title{
Salivary pellicles on titanium and their effect on metabolic activity in Streptococcus oralis
}

\author{
Marjan Dorkhan, Gunnel Svensäter and Julia R Davies
}

\begin{abstract}
Background: Titanium implants in the oral cavity are covered with a saliva-derived pellicle to which early colonizing microorganisms such as Streptococcus oralis can bind. The protein profiles of salivary pellicles on titanium have not been well characterized and the proteins of importance for binding are thus unknown. Biofilm bacteria exhibit different phenotypes from their planktonic counterparts and contact with salivary proteins may be one factor contributing to the induction of changes in physiology. We have characterized salivary pellicles from titanium surfaces and investigated how contact with uncoated and saliva-coated titanium surfaces affects metabolic activity in adherent cells of S. oralis.

Methods: Salivary pellicles on smooth titanium surfaces were desorbed and these, as well as purified human saliva, were subjected to two-dimensional gel electrophoresis and mass spectroscopy. A parallel plate flow-cell model was used to study binding of a fresh isolate of $S$. oralis to uncoated and saliva-coated titanium surfaces. Metabolic activity was assessed using the BacLight CTC Vitality Kit and confocal scanning laser microscopy. Experiments were carried out in triplicate and the results analyzed using Student's t-test or ANOVA.

Results: Secretory IgA, a-amylase and cystatins were identified as dominant proteins in the salivary pellicles. Selective adsorption of proteins was demonstrated by the enrichment of prolactin-inducible protein and absence of zinc- $\mathrm{a}_{2}$-glycoprotein relative to saliva. Adherence of $\mathrm{S}$. oralis to titanium led to an up-regulation of metabolic activity in the population after 2 hours. In the presence of a salivary pellicle, this effect was enhanced and sustained over the following 22 hour period.

Conclusions: We have shown that adherence to smooth titanium surfaces under flow causes an up-regulation of metabolic activity in the early oral colonizer S. oralis, most likely as part of an adaptation to the biofilm mode of life. The effect was enhanced by a salivary pellicle containing slgA, a-amylase, cystatins and prolactin-inducible protein which was, for the first time, identified as an abundant component of salivary pellicles on titanium. Further studies are needed to clarify the mechanisms underlying the effect of surface contact on metabolic activity as well as to identify the salivary proteins responsible for enhancing the effect.
\end{abstract}

Keywords: Bacteria, Microbial biofilm, Dental implant, Streptococci

\section{Background}

The human oral cavity harbours a large number of different bacterial species which are found in complex, multi-species biofilms. On teeth, these biofilms are commonly known as dental plaque. Critical to the formation and development of plaque is the adherence of pioneer species such as Streptococcus oralis, Streptococcus mitis and Streptococcus gordonii as well as Actinomyces naeslundii to the salivary

\footnotetext{
* Correspondence: Julia.Davies@mah.se

Department of Oral Biology, Faculty of Odontology, Malmö University, Malmö SE-20506, Sweden
}

pellicle which coats the tooth surface [1,2]. Once biofilm formation has been initialized and the nascent tooth surface is colonized, co-adherence of later colonizers leads to the formation of mature oral biofilms [3]. The early development of biofilms on dental implants has not been well characterized but the sequence of microbial colonization is thought to be similar to that for teeth in the same oral cavity $[4,5]$.

Teeth and dental implants, as well as the mucosal surfaces, are covered with a pellicle which is a thin film of adsorbed proteins mainly derived from saliva.

\section{Ciomed Central}


Pellicle proteins provide an array of potential receptors for the attachment of the early colonizers. A combination of in vivo and in vitro studies using antibody-based and proteomics approaches, has shown that the acquired enamel pellicle contains a range of different salivary proteins including lysozyme, histatins, statherins [6], $\alpha$-amylase, cystatins, secretory $\operatorname{IgA}(\operatorname{sg} \mathrm{A})$, lactoferrin and proline-rich proteins (Prps) [7] as well as the large salivary mucin, MUC5B [8]. For a comprehensive summary of proteins detected in enamel pellicles see Siquiera et al., 2012 [9]. The composition of an adherent pellicle, as well as the density and conformation of the proteins present in it, is generally thought to be influenced by the physico-chemical properties of the substratum but, as yet, the overall composition of the salivary pellicles formed on differently modified titanium surfaces are unknown. Despite the existence of only a few studies, some salivary proteins including cystatins, $\operatorname{sigA}, \alpha$-amylase and proline-rich proteins have been identified in the adherent pellicle formed on titanium in vitro using Western blotting $[10,11]$. However in all such studies, the methods used to prepare saliva for use as a pellicle can have a large impact on the results obtained. For instance, filtering and centrifugation techniques may remove major populations of salivary proteins leading to the formation of salivary pellicles which are not representative of those present in vivo.

The recognition that microbial biofilms are an important factor associated with the failure of dental implants [12] has led to many investigations of bacterial adhesion to titanium surfaces. In vivo, where adherence of bacteria and salivary pellicle formation occur in parallel, S. oralis and $S$. mitis were amongst the predominant early colonizers on titanium-coated glass surfaces and no Actinomyces species were found [13]. In vitro, the presence of saliva on both smooth or moderately-rough surfaces has been shown to both increase and decrease the adherence of the early colonizer, S. oralis, [10,14] while binding of A. naeslundii to titanium was unaffected by the presence of a salivary pellicle [11]. Overall, the results of studies of bacterial adherence to titanium in the presence of saliva have not yielded a clear picture and while some of the differences seen may attributable to the saliva used, variation in the bacterial strains and types of titanium surface may also contribute to the lack of consensus.

While biofilm development is important for the development of oral disease, a crucial contributory factor is the physiology and level of activity of the adhered bacteria. Bacterial adaptation to the biofilm mode of life is known to be associated with major changes in transcription and protein synthesis [15]. For example, in Porphyromonas gingivalis comparative transcriptomic analysis revealed that a large number of genes are differentially expressed in biofilm cells compared to their free-floating counterparts
[16]. In a study in Streptococcus mutans, the relative rate of synthesis of at least 25 different proteins was enhanced within 2 hours of attachment to a glass surface. These proteins were mostly associated with carbohydrate catabolism [17] suggesting that changes in metabolic activity may occur during adhesion to surfaces. Little is currently known, however, about the metabolic status of cells during interactions with pellicle proteins in the early stages of biofilm formation. The aim of this work was to study how adherence to titanium surfaces affects the metabolic activity of the early colonizer $S$. oralis and to determine the effect of a salivary pellicle on this process. To shed light upon which salivary proteins may influence adherence and metabolic activity, the predominant proteins present in a salivary pellicle formed on titanium have been identified.

\section{Methods}

\section{Bacteria and culture conditions}

A fresh clinical isolate of $S$. oralis (89C) was obtained from a patient with an on-going peri-implant infection after ethical approval had been obtained from the Faculty of Odontology [14]. Bacteria were grown overnight on blood agar in an atmosphere of $5 \% \mathrm{CO}_{2}$ in air at $37^{\circ} \mathrm{C}$. Colonies were suspended in $120 \mathrm{ml}$ phosphate buffered saline [0.15M NaCl, 10mM NaH $\mathrm{mO}_{4}, \mathrm{pH} 7.4$ (PBS)] to give an $\mathrm{OD}_{600 \mathrm{~nm}}=0.6$. For the flow-cell experiments, an equal volume of PBS was added to halve the cell concentration prior to biofilm formation, whereas for the planktonic experiments the original bacterial suspension was mixed with an equal volume of either PBS, or $50 \%$ whole human saliva to give a final concentration of $25 \%$ saliva.

\section{Collection and preparation of saliva}

Whole saliva collected on ice over 1 hour from ten healthy individuals was pooled and prepared as described previously [18] after ethical approval had been obtained from the Faculty of Odontology. Briefly, the sample was mixed with an equal volume of PBS, stirred gently overnight at $4^{\circ} \mathrm{C}$ and centrifuged in a Beckman Coulter Avanti J-E centrifuge (Beckman JA 20 rotor; Beckman Coulter, Brea, CA) (20 minutes, $30000 \mathrm{~g}, 4^{\circ} \mathrm{C}$ ). The supernatant was then subjected to isopycnic density-gradient centrifugation in $\mathrm{CsCl} / 0.1 \mathrm{M} \mathrm{NaCl}$ in a Beckman Coulter Optima LE-80K Ultracentrifuge (Beckman 50.2 Ti rotor, starting density $1.45 \mathrm{~g} \mathrm{ml}^{-1}$ ) at $36000 \mathrm{rpm}$ for 90 hours at $15^{\circ} \mathrm{C}$. Fractions containing bacteria were discarded and those remaining were pooled, dialysed against PBS and stored at $-20^{\circ} \mathrm{C}$.

\section{Titanium surfaces}

The titanium surfaces used in this study were of commercially pure grade IV titanium, which was smooth, with an average surface roughness $\left(\mathrm{S}_{\mathrm{a}}\right)$ of $0.1 \mu \mathrm{m}$ [14]. The plates $(99 \times 25 \times 0.8 \mathrm{~mm})$ were turned, cleaned with detergent, 
rinsed with distilled water and sterilized using $\gamma$ irradiation (ELOS Pinol A/S).

\section{Characterization of saliva pellicles}

Two titanium plates, separated by a rubber spacer with thickness of $1.6 \mathrm{~mm}$, were mounted in a flow-cell and the surfaces coated with $50 \%$ whole human saliva overnight. After this time the flow-cells were drained and the surfaces washed $(2 \times 2$ mins $)$ with PBS on a rocking plate. To remove the surface-associated pellicles, a mixture of Tween $80(0.006 \mathrm{v} / \mathrm{v} \%)$ and Triton X-100 $(0.012 \mathrm{v} / \mathrm{v} \%)$ was introduced and the whole flow-cell placed in an ultrasonic bath for 1 hour. The contents were then drained and collected before repeating this step for an additional 15 minutes. Protein desorbates collected after each wash were pooled and the protein concentration determined using a 2D Quant kit (GE Healthcare Life Sciences). A volume corresponding to $20 \mu \mathrm{g}$ protein was subjected to 2DE. Briefly, the desorbate was diluted with rehydration buffer and placed in a re-swelling cassette with $18 \mathrm{~cm} \mathrm{pH}$ 4-7 linear IPG strips (GE Healthcare Life Sciences) on top. Rehydration was undertaken at room temperature for 30 hours under silicone oil. Isoelectric focusing was carried out using a Multiphor II (GE Healthcare Life Sciences) with cooling water at $15^{\circ} \mathrm{C}$ supplied by Pharmacia Multitemp II. The focusing was initiated at $150 \mathrm{~V}$ for 1 hour and continued at $300 \mathrm{~V}$ for 3 hours, $600 \mathrm{~V}$ for 3 hours, $1200 \mathrm{~V}$ for 12 hours and finally $3,500 \mathrm{~V}$ for 20 hours. After focusing, the IPG strips were stored at $-80^{\circ} \mathrm{C}$. Before running in the second dimension, the IPG strips were equilibrated first in 50 mM Tris buffer pH 6.8 containing 2\% SDS, 26\% glycerol and $16 \mathrm{mM}$ DTT for 15 minutes and then in $50 \mathrm{mM}$ Tris buffer pH 6.8 containing 2\% SDS, 26\% glycerol, $250 \mathrm{mM}$ iodoacetamide and $0.005 \%$ bromophenol blue for another 15 minutes. The equilibrated IPG strips were embedded on top of $14 \%$ polyacrylamide gels $(20 \times 20 \times 0.1 \mathrm{~cm})$ using $0.5 \%(\mathrm{w} / \mathrm{v})$ molten agarose. SDS-PAGE was performed at a constant current of $15 \mathrm{~mA} \mathrm{gel}^{-1}, 10^{\circ} \mathrm{C}$, overnight in a PROTEAN II xi cell (Bio-Rad) with rainbow high-range molecular mass standards (GE Healthcare Life Sciences) run on the acidic side of the IPG strips. Gels were stained with Coomassie brilliant blue or silver according to the protocols from GE Healthcare Life Sciences.

\section{Identification of proteins on 2D gels by LC-MS/MS}

Spots of interest were excised manually from Coomassie brilliant blue stained 2DE gels of whole saliva and subjected to LC-MS/MS as described previously [19]. Briefly, proteins were reduced with DTT $\left(60^{\circ} \mathrm{C}, 20\right.$ minutes $)$, alkylated with iodoacetamide $\left(25^{\circ} \mathrm{C}, 10\right.$ minutes) and then digested with trypsin $\left(37^{\circ} \mathrm{C}, 8\right.$ hours). Tryptic peptides were separated and subjected to MS. Peptide peaks were deconvoluted automatically and mass lists in the form of Mascot Generic Files used as the input for Mascot MS/MS Ions searches of the NCBInr database using the Matrix Science web server (www.matrixscience.com).

\section{Determination of surface coverage and viability}

Viability of cells suspended in PBS or 25\% whole saliva was assessed by staining a drop of the suspension with the Live/Dead BacLight staining kit (Life Technologies, Stockholm, Sweden) at baseline (time 0), after 2 and 24 hours and viewing with an inverted confocal laser scanning microscope (CSLM) (Eclipse TE2000, Nikon Corp.). The vertical, parallel plate flow-cell system used has been described previously (14). Briefly, S. oralis cells were passed over two titanium surfaces $(99.25 \times 25.25 \times 0.8 \mathrm{~mm})$ separated by a $1.6 \mathrm{~mm}$ rubber spacer, which were either uncoated or had been coated with saliva overnight. All experiments were carried out at $37^{\circ} \mathrm{C}$ and a laminar flow of $42 \mathrm{ml} \mathrm{h}^{-1}$ was used to model the daily flow of saliva over the oral surfaces. All solutions were introduced through the lower inlet and outflow occurred through the upper valve. Initially, surfaces were rinsed with PBS for 30 minutes. The same bacterial suspension was then introduced into two flow-cells; one containing two uncoated surfaces and the other containing two saliva-coated surfaces for 2 or 24 hours at $37^{\circ} \mathrm{C}$. After this time, the flow-cells were washed with PBS (as above) for 30 minutes to remove loosely attached bacteria from the surfaces. Surface coverage and viability of surface-associated cells were assessed on one of the titanium plates in each flow-cell using Live/Dead BacLight staining. Experiments were carried out three times using independent bacterial cultures.

\section{Determination of metabolic activity}

To investigate metabolic activity of planktonic cells, an aliquot was removed from the same bacterial suspension used for the viability measurements, placed in an ibidi flow-cell chamber and the cells incubated with the BacLight CTC Vitality Kit (Life Technologies, Stockholm, Sweden) in a humid chamber at $37^{\circ} \mathrm{C}$ for 2 hours. The slides were then viewed using a CSLM. To investigate the metabolic activity of adhered cells, the second titanium plate in each flow-cell, was incubated with the BacLight CTC Vitality Kit as above and the cells then counterstained with 4', 6-diamidino-2-phenylindole (DAPI, Life Technologies, Stockholm, Sweden). Stained cells were visualized using a CSLM.

\section{Image analysis and statistics}

For samples stained with the Live/Dead BacLight staining kit, ten random images each with an area of $127.3 \mu \mathrm{m}^{2}$ were taken for image analysis. Images were analysed using the bioImage_L software package to quantitate the average surface coverage as well as the proportion of live (green) and dead (red) cells [20]. For samples stained with the BacLight CTC Vitality Kit to assess metabolic 


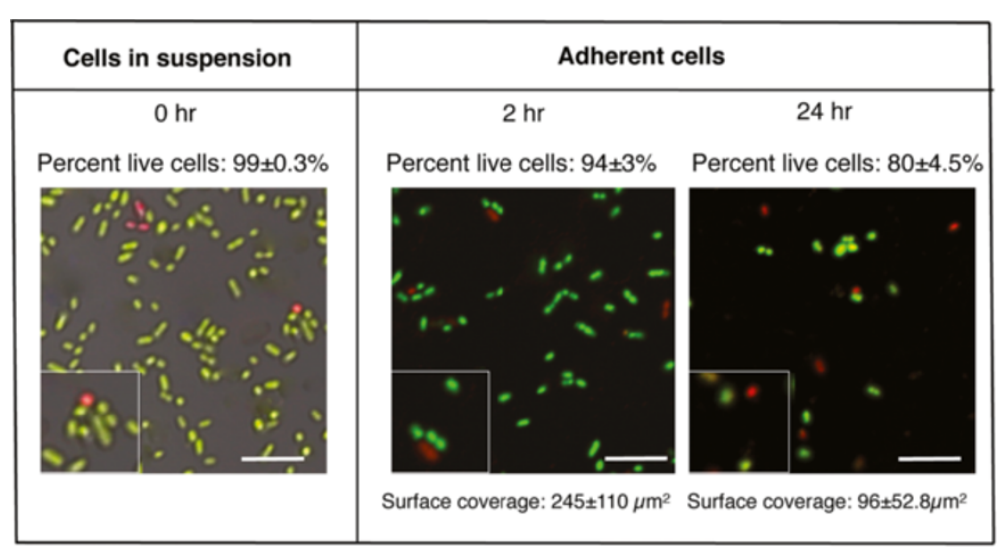

Figure 1 Images showing biofilm formation by S. oralis on uncoated titanium surfaces. Bacteria suspended in PBS were allowed to form biofilms on titanium surfaces in a parallel plate flow-cell system for 2 and 24 hours. The viability of the cells was assessed by Live/Dead BacLight staining and viewing with CSLM. Surface coverage on the titanium plates was assessed from ten random images using the biolmage_L software package. The scale bars represent $10 \mu \mathrm{m}$ and the inserts show cells in twofold enlargement.

activity, image analysis was performed by observing at least 1000 cells and counting the number of metabolically active cells (red/pink) and non-active cells (unstained in the suspension samples or counterstained blue on the titanium surfaces). The results obtained were evaluated using Student's $t$-test to compare two groups or a one-way ANOVA with the Bonferroni post-test to compare three groups. A confidence interval of $95 \%$ was chosen and $\mathrm{p}$ values below 0.05 were considered significant.

\section{Results}

Biofilm formation on titanium in flow-cells

The biofilm-forming ability of $S$. oralis was investigated in a flow-cell system containing two uncoated titanium surfaces. Bacterial colonies dispersed in PBS were introduced into flow-cells and allowed to adhere for 2 or 24 hours. After 24 hours, the average surface coverage was decreased by $60 \%$ compared to that after 2 hours, suggesting that some of the cells which adhered initially detached over time (Figure 1). In the initial cell suspension the level of viability was high as revealed by staining with the BacLight Live/Dead kit. After 2 and 24 hours, the viability of the adherent populations was not significantly different to that of the original suspension, indicating that binding to titanium did not adversely affect the cells. Since surfaces in the oral cavity are covered with a salivary pellicle, we investigated the effect of saliva on adherence and viability of $S$. oralis. On surfaces coated with $25 \%$ saliva, the average surface coverage after 2 hours $\left(178 \pm 103 \mu \mathrm{m}^{2}\right)$ was not significantly different to that seen on the uncoated surfaces $(\mathrm{p}=0.67)$ (data not shown). As for the uncoated surfaces, after 24 hours

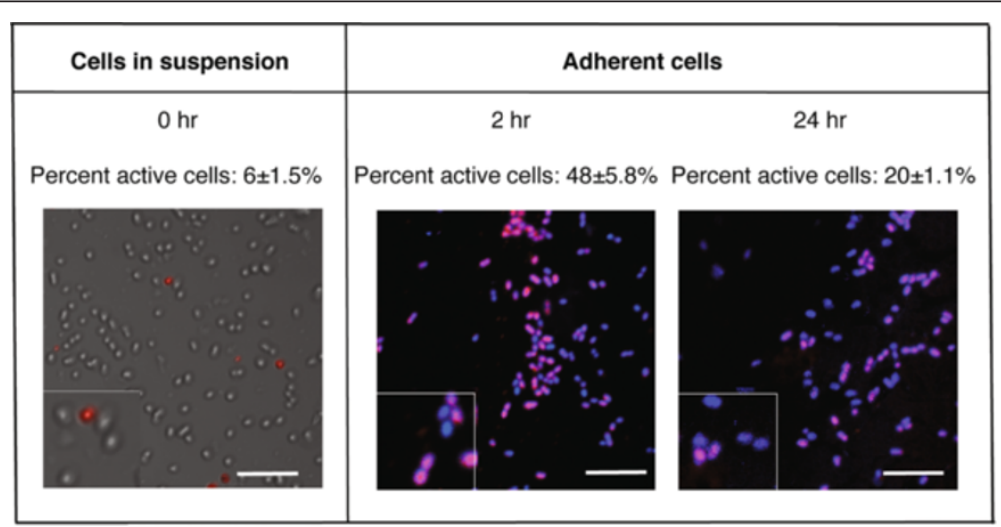

Figure 2 Images showing metabolic activity of $\boldsymbol{S}$. oralis in suspension and adhered to uncoated titanium surfaces. Bacteria suspended in PBS were allowed to form biofilms on titanium surfaces in a parallel plate flow-cell system for 2 and 24 hours. The metabolic activity of the cells was assessed using the BacLight CTC Vitality Kit. For adhered cells, DAPI was used as a counterstain. Cells were viewed with CSLM and the proportion of metabolically active (red/pink) cells assessed by manually counting at least 1000 cells. The scale bars represent $10 \mu \mathrm{m}$ and the inserts show cells in twofold enlargement. 
the average surface coverage on the saliva coat had declined $\left(24.6 \pm 7.4 \mu \mathrm{m}^{2}\right)$, demonstrating that bacterial cells also detached from these surfaces over time. The level of viability of the cells on the saliva-coated surface was not significantly different to that on the uncoated surface at the same time point.

\section{Metabolic activity in relation to contact with uncoated and saliva-coated surfaces}

Metabolic activity of $S$. oralis cells was assessed using the BacLight CTC Vitality Kit, where metabolically active cells reduce the colourless tetrazolium salt to an insoluble formazan product causing them to appear red (or pink in the presence of the blue DAPI counterstain). Cells removed from blood agar at time 0 and dispersed in PBS showed a low level of endogenous metabolic activity $(6 \pm 1.5 \%)$ (Figure 2$)$. Continued incubation of the cells in PBS had no significant effect on the level of metabolic activity after 2 hours $(4 \pm 0.5 \%)$ or 24 hours $(2 \pm 0.1 \%)$. However, after 2 hours in the flow-cell model, the adherent population contained a significantly higher proportion of red cells indicating that metabolic activity was stimulated by contact with a surface. After 24 hours, the level of metabolic activity within the adherent population had decreased but was still significantly greater than in the original PBS suspension $(\mathrm{p}<0.01)$.

The effects of saliva coating on the metabolic activity of adherent bacteria were then investigated. This revealed that the levels were significantly higher for cells associated with the saliva-coated surface after 2 hours and 24 hours compared to those in the original PBS suspension $(\mathrm{p}<0.001)$ (Figure 3). Incubation of bacteria with $25 \%$ saliva in suspension caused no significant change in metabolic activity over 2 hours $(4 \pm 0.5 \%)$ or 24 hours $(3 \pm 0.6 \%)$ suggesting that the effect was specific to salivary proteins adhered to a surface. These data thus show that adsorbed salivary proteins have the capacity to elicit a metabolic response that is not seen when the proteins are present in solution.

Since non-viable cells on the surfaces are not expected to show metabolic activity, to investigate the level of metabolic activity as a function of the number of viable cells, a ratio was calculated for each time point (Table 1). This revealed that for cells suspended in PBS or saliva, while viability was maintained, there were no significant changes in metabolic activity over time. Adherence to an uncoated surface caused the proportion of the viable cells that were metabolically active to rise to $50 \%$ after 2 hours, whereas binding to a saliva pellicle significantly increased this level to $98 \%$ of the viable cells $(p<0.001)$. Thus while initial contact with a surface caused an increase in metabolic activity within the population, this was greatly enhanced by the presence of a salivary pellicle. After 24 hours, the proportion of metabolically

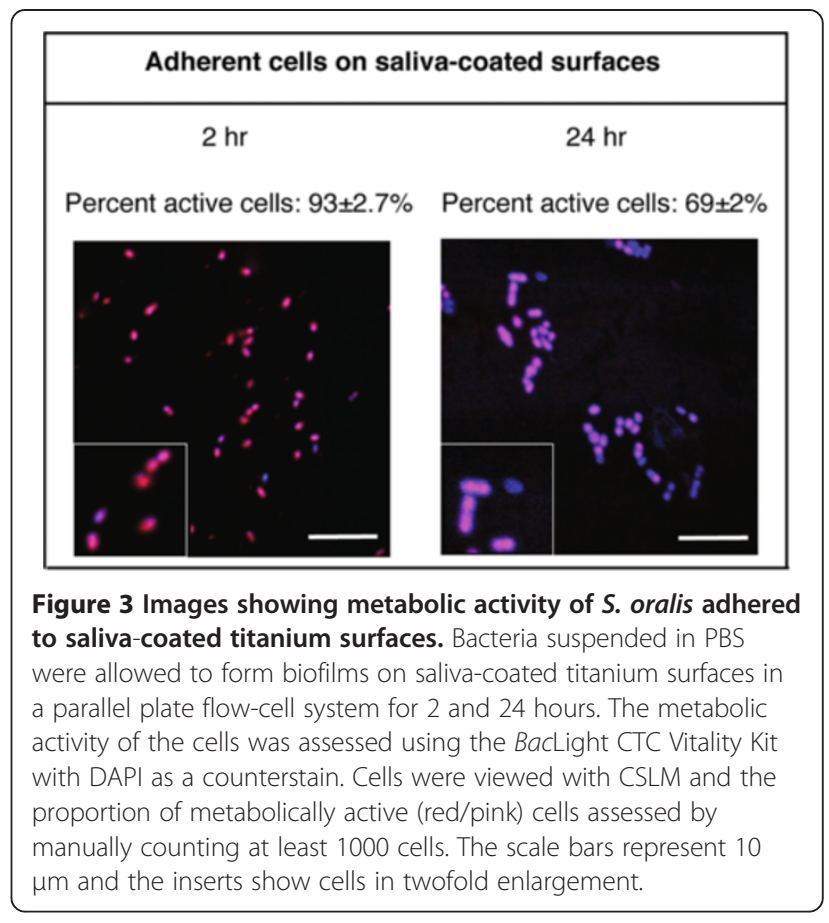

active cells on the uncoated titanium surface had decreased to $25 \%$ whereas on the saliva-coated surface the level remained at $96 \%$. This suggests that, in addition to enhancing the initial response to surface contact, the presence of salivary proteins sustained the increase in metabolic activity over 24 hours.

\section{Characterisation of saliva coating on titanium surfaces}

To identify the major protein components in the bacteriafree saliva preparation, the material was subjected to $2 \mathrm{DE}$ and proteins visualised by staining with Coomassie brilliant blue (Figure 4a). This revealed the presence of over 100 spots, of which the majority (70) were picked, and 68 of these could be identified using LC-MS/MS (Table 2). Almost all the proteins present were shown to be of salivary origin, with secretory IgA, zinc- $\alpha_{2}$-glycoprotein, members of the cystatin family, $\alpha$-amylase and prolactininduced protein (PIP) as the dominant species in the

Table 1 Proportion of viable bacteria in the population showing metabolic activity under different conditions

\begin{tabular}{lccc}
\hline Environment & \multicolumn{3}{c}{$\begin{array}{c}\text { \% live cells with } \\
\text { metabolic activity }\end{array}$} \\
\cline { 2 - 4 } & $\mathbf{0 ~ \mathbf { ~ h }}$ & $\mathbf{2 ~ \mathbf { ~ }}$ & $\mathbf{2 4} \mathbf{~ h}$ \\
\hline Cells suspended in PBS & $6 \pm 1.5$ & $4 \pm 0.5$ & $2 \pm 0.03$ \\
Cells adhered to uncoated surfaces in PBS & - & $50 \pm 4.5$ & $25 \pm 2.6$ \\
Cells suspended in 25\% saliva & - & $4 \pm 0.8$ & $3 \pm 0.6$ \\
Cells adhered to surfaces coated & - & $98 \pm 4.3$ & $96 \pm 6.3$ \\
with 25\% saliva & & & \\
\hline
\end{tabular}



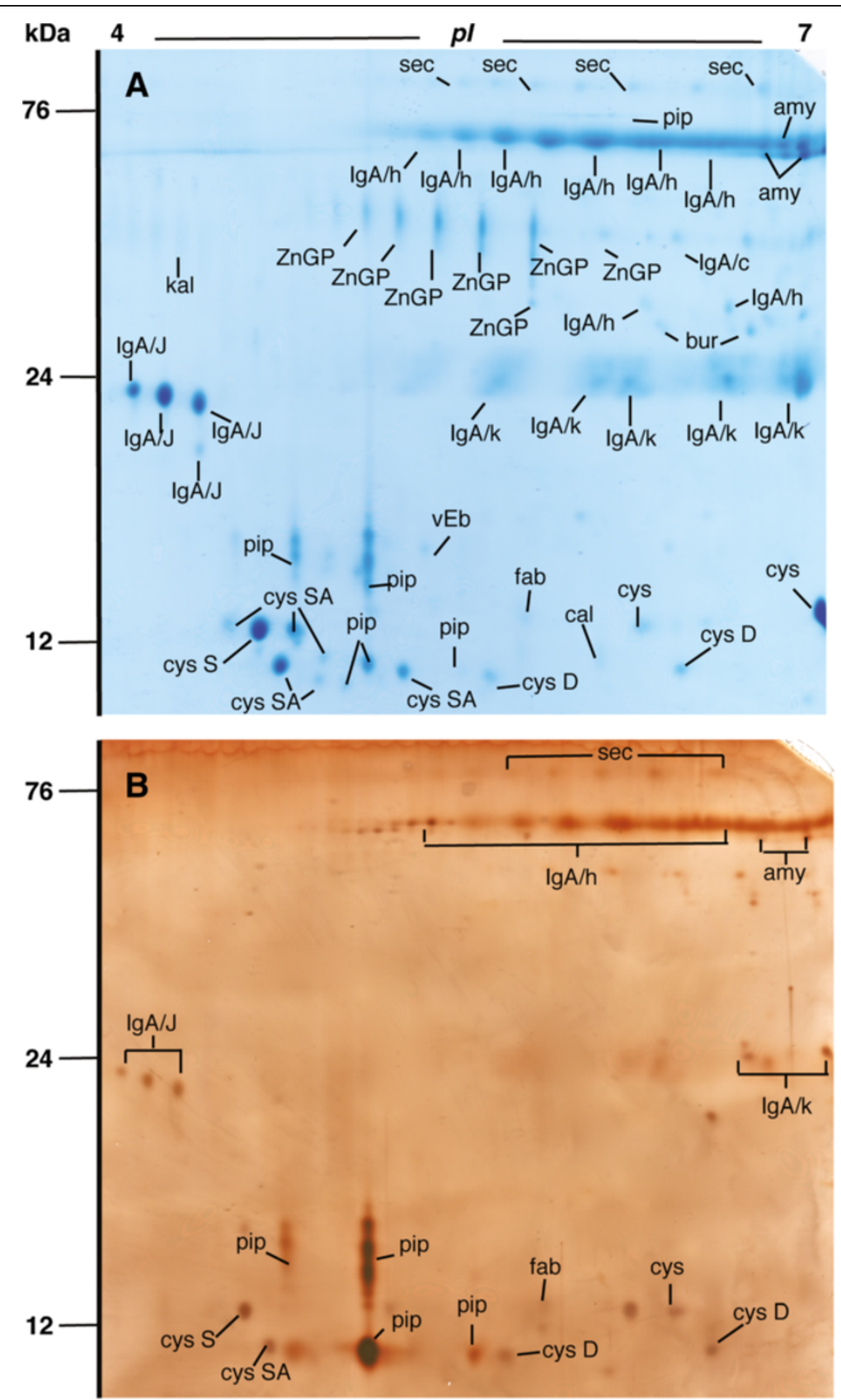

Figure 4 2DE gels of whole saliva and the salivary pellicle desorbed from titanium surfaces. Pooled whole human saliva (A) and salivary pellicles desorbed from titanium surfaces using detergent (B) were subjected to isoelectric focussing on pH 4-7 IPG strips followed by SDS-PAGE on $14 \%$ gels. Gels were stained with Coomassie Blue (A) or silver (B). Spots of interest were picked from the Coomassie gel, identified using LC-MS/MS and spot identities transferred to the silver gel. An explanation of the labels is given in Table 2 .

preparation. In addition, kallikrein, fatty acid-binding protein and von Ebner's protein were identified.

To identify the proteins present in the salivary pellicle formed on titanium, surfaces were incubated overnight with saliva and, after washing, the adhered proteins were desorbed with detergent and subjected to 2DE (Figure 4b). Silver staining of the gels revealed around 50 spots of which all were seen in the Coomassie stained saliva gel. Secretory IgA, cystatin proteins, $\alpha$-amylase and PIP were present but zinc- $\alpha_{2}$-glycoprotein was absent indicating that this protein did not adhere to the titanium surface. The relative intensity of PIP spots in the pellicle was greater than in the original saliva preparation suggesting that this protein might be enriched on the titanium surface. 
Table 2 Identities of proteins from whole saliva or salivary pellicles desorbed from titanium surfaces using detergent obtained using LC-MS/MS of spots from 2DE gels.

\begin{tabular}{lccc}
\hline Protein identity & $\begin{array}{c}\text { Spot } \\
\text { name }\end{array}$ & $\begin{array}{c}\text { \% Sequence } \\
\text { coverage }\end{array}$ & $\begin{array}{c}\text { Detected on } \\
\text { surface }\end{array}$ \\
\hline Amylase & amy & $45-55$ & Yes \\
Calgranulin & cal & 49 & No \\
Cystatin & cysS & 77 & Yes \\
S & cysSA & $37-73$ & Yes \\
SA & cysD & 31 & Yes \\
D & fab & 51 & Yes \\
Fatty acid binding protein & & & \\
Immunoglobulin A & IgA/J & $37-63$ & Yes \\
J chain & IgA/h & $18-36$ & Yes \\
Heavy chain & IgA/C & 21 & No \\
Heavy chain C region & $\mathrm{sec}$ & $32-36$ & Yes \\
Secretory component & $\mathrm{Bur}$ & $11-15$ & No \\
Bur & & & \\
Immunoglobulin & $\mathrm{Ig} / \mathrm{k}$ & $38-59$ & Yes \\
Light chain (kappa) & $\mathrm{kal}$ & 10 & No \\
Kallikrein & $\mathrm{pip}$ & $63-67$ & Yes \\
Prolactin-inducible protein & $\mathrm{vEb}$ & 27 & No \\
Von Ebners's gland protein & & & No \\
(lipocalin) & $\mathrm{ZnGP}$ & $23-45$ & \\
Zinc-a2-glycoprotein & & &
\end{tabular}

\section{Discussion}

Early colonizers such as $S$. oralis initiate biofilm formation by interacting directly with the salivary pellicle that is present on oral surfaces. In this study, we have used pellicles of saliva prepared by density-gradient centrifugation under non-denaturing conditions. The advantage of this technique is that salivary bacteria, which are pelleted, can be separated from large macromolecules allowing the preparation of bacteria-free, 'native' saliva in which even large salivary proteins are present. We have previously identified the two large salivary mucins (MUC5B and MUC7) as well as gp340, lysozyme, lactoferrin, $\alpha$-amylase, secretory IgA and statherin in this preparation using ELISA [21]. In this study, we performed 2DE in combination with LC-MS/MS to identify lower molecular-weight salivary proteins (Figure 4a). Secretory IgA was the most abundant protein as revealed by the presence of several fragments (secretory component, heavy chain, $\mathrm{k}$-chain and J-chain). In agreement with analyses of human saliva by other groups using proteomics approaches $[7,22]$ we were also able to identify $\alpha$-amylase, proteins of the cystatin family, zinc- $\alpha_{2^{-}}$ glycoprotein and PIP. Fatty acid binding protein, kallikrein and von Ebners gland protein (lipocalin) were present in minor amounts. In this study we have applied the methodology to examine the salivary pellicles formed on titanium. This showed that sIgA and $\alpha$-amylase were the most abundant proteins in the pellicle in addition to members of the cystatin protein family and PIP (Figure 4b). Previous studies using SDS-PAGE combined with Western blot analysis with specific antibodies against salivary proteins, have shown that $\alpha$-amylase, sIgA and Prps bind to titanium $[10,11]$. Zinc- $\alpha_{2}$-glycoprotein was absent from the pellicle desorbate suggesting that this protein does not adhere to titanium whereas the greater relative abundance of PIP in the desorbate than in the original saliva preparation indicates that the protein is enriched on the surface. Oral bacteria such as S. salivarius, S. parasanguinis and $S$. oralis can interact with PIP [23,24], suggesting that this protein could play an important role in modulating bacterial colonization of oral surfaces. To our knowledge, this is the first time that PIP has been identified as an abundant protein in pellicles on titanium. A $20 \mathrm{kDa}$ protein corresponding to PIP [25] has previously been demonstrated to bind to hydroxyapatite but was not enriched in the same way found here [26]. One limitation of this study however is that it is currently unknown whether the results are applicable to other titanium surfaces with differing surface topographies or surface modifications.

In the flow-cell model, $S$. oralis adhered well to salivacoated surfaces after 2 hours - in keeping with other studies on primary colonizers such as Streptococcus anginosus, Streptococcus gordonii and Streptococcus sanguinis [10] and Actinomyces naeslundii [11]. As a group, oral streptococci are known to express adhesins which have affinity for a range of proteins present in saliva [27]. In a previous study, we identified a 1060 amino-acid-containing, LPXTG-linked protein expressed in strains of $S$. oralis which bound well to salivary pellicles and in silico analysis of the $S$. oralis genome revealed a further two LPXTG-linked putative adhesins [14]. Little is however known about specific adhesins present on S. oralis and the ligands to which the previously identified adhesins bind are currently unidentified.

In this study, the fluorescent redox indicator CTC, which gives rise to red, insoluble product when reduced by intracellular electron transport activity, was used as a marker of metabolic activity [28]. This technique has been used previously to investigate the activity of Staphylococcus aureus and Staphylococcus epidermidis on albumin-coated titanium surfaces [29]. In oral streptococci, the major energy-generating pathway which results in high NADH/ $\mathrm{NAD}+$ ratios, and thus red staining within the cells, is the glycolytic pathway. We have shown that adherence of cells to uncoated titanium under flow led to an increase in metabolic activity within the viable bacteria population from $6 \%$ to $50 \%$ within the first 2 hours (Figure 2). This suggests that, even in the absence of nutrients, surface contact activated energy-generating 
pathways within the cells. During transition from the planktonic to the biofilm mode of life, microorganisms are well known to undergo major transcriptional and proteomic changes [15]. For example, synthesis of a range of enzymes in the glycolytic pathway including dehydrogenases and kinases has been shown to be enhanced during early biofilm formation [17]. In addition, transcriptional studies in P. gingivalis have shown that $18 \%$ of the genome is differentially regulated in adherent cells compared to those in suspension, with changes in expression of genes associated with cell envelope synthesis, DNA replication and metabolism [16]. Since in E coli, it has been proposed that the activity of the glycolytic pathway is regulated by the demand for ATP [30], the requirement for energy to drive anabolic processes associated with surface contact could explain the increase in metabolic activity seen in our study. The stimulatory effect of surface contact was doubled by the presence of a saliva coat, where $93 \%$ of the viable population was metabolically active after 2 hours (Figure 4, Table 2) and the effect was sustained over the following 22 hours. This increase was not seen in bacteria in contact with the same preparation of saliva in solution, suggesting that the conformation of the proteins is important for the response. Thus we have shown that surface-associated salivary proteins have the capacity to influence the metabolic status of adherent S. oralis cells. However, this study is limited by the use of one strain of $S$. oralis and further studies are therefore required to determine whether the results can be generalized to other oral bacteria as well as to identify mechanisms underlying the effect and the salivary proteins responsible.

\section{Conclusions}

In conclusion, we have shown that adherence to smooth titanium surfaces is associated with an up-regulation of metabolic activity in the early oral colonizer S. oralis, most likely as part of an adaption to the biofilm mode of life. The effect was enhanced by the presence of a salivary pellicle which was shown to contain a number of proteins including sIgA, $\alpha$-amylase, cystatins and PIP which, for the first time, was identified as an abundant component of salivary pellicles on titanium. Further studies are now required to clarify the mechanisms underlying the effect of surface contact on metabolic activity as well as to identify the salivary proteins responsible for the effect.

\section{Abbreviations}

CSLM: Confocal scanning laser microscopy; 2DE: Two-dimensional SDSPolyacrylamide gel electrophoresis; DAPI: 4',6-diamidino-2-phenylindole; PBS: $0.15 \mathrm{M}$ sodium chloride, $10 \mathrm{mM}$ sodium dihydrogen phosphate, $\mathrm{pH}$ 7.4.

\section{Competing interests}

The authors declare that they have no competing interests.

\section{Authors' contributions}

MD participated in planning and designing the study, performed most of the laboratory work and participated in the data analysis as well as drafting of the manuscript. GS and JRD participated in study design, data analysis and drafting of the manuscript. All authors have read and approved the final manuscript.

\section{Acknowledgements}

The authors would like to thank Agnethe Henriksson for excellent technical assistance and Lennart Carlsson and Christian Schärfe Thomsen for providing the titanium surfaces. We would also like to thank The Aberdeen Proteome Facility which is funded jointly by the SHEFC, BBSRC and the University of Aberdeen for help with protein identification using LC-MS/MS. MD is a member of The Swedish National Graduate School in Odontological Science. The study was funded by the Stiftelsen för Odontologisk Forskning i Malmö, the Swedish Dental Society and the Knowledge Foundation, Sweden.

Received: 27 March 2013 Accepted: 8 July 2013

Published: 16 July 2013

\section{References}

1. Nyvad B, Kilian M: Microbiology of the early colonization of human enamel and root surfaces in vivo. Scand J Dent Res 1987, 95:369-380.

2. Dige I, Raarup MK, Nyengaard JR, Kilian M, Nyvad B: Actinomyces naeslundii in initial dental biofilm formation. Microbiology 2009, 155:2116-2126.

3. Kolenbrander PE, Palmer RJ, Periasamy S, Jakubovics NS: Oral multispecies biofilm development and the key role of cell-cell distance. Nat Rev Microbiol 2010, 8:471-480.

4. Lee KH, Maiden MF, Tanner AC, Weber HP: Microbiota of successful osseointegrated dental implants. J Periodont 1999, 70:131-138.

5. Tanner A, Maiden MF, Lee K, Shulman LB, Weber HP: Dental implant infections. Clin Infect Dis 1997, 25(Suppl 2):S213-S217.

6. Yao Y, Berg EA, Costello CE, Troxler RF, Oppenheimer FG: Identification of protein components in human acquired enamel pellicle and whole saliva using novel proteomics approaches. J Biol Chem 2003, 278:5300-5308.

7. Vitorino R, Lobo MJC, Ferrer-Corriera AJ, Dublin JR, Tomer KB, Domingues PM, Amado FML: Identification of human whole saliva protein components using proteomics. Proteomics 2004, 4:1109-1115.

8. Al-Hashimi I, Levine MJ: Characterization of in vivo salivary-derived enamel pellicle. Arch Oral Biol 1989, 34:289-295.

9. Siquiera WL, Custodio W, McDonald EE: New insights into the composition and functions of the acquired enamel pellicle. J Dent Res 2012 , 91:1110-1118.

10. Edgerton M, Lo SE, Scannapieco FA: Experimental salivary pellicles formed on titanium surfaces mediate adhesion of streptococci. Int J Oral Maxillofac Implants 1996, 11:443-449.

11. Lima EM, Koo H, Vacca Smith AM, Rosalen PL, Del Bel Cury AA: Adsorption of salivary and serum proteins and bacterial adherence on titanium and zirconia ceramic surfaces. Clin Oral Implants Res 2008, 19:780-785.

12. Esposito M, Hirsch JM, Lekholm U, Thomsen P: Biological factors contributing to failures of osseointegrated oral implants. (II). Etiopathogenesis. Eur J Oral Sci 1998, 106:721-764.

13. Grössner-Schreiber B, Teichmann J, Hannig M, Dörfer C, Wenderoth DF, Ott SJ: Do different implant surfaces exposed in the oral cavity of humans show different biofilm compositions and activities? Clin Oral Implants Res 2009, 20:817-826.

14. Dorkhan M, Chavez de Paz LE, Skepo M, Svensater G, Davies JR: Effects of saliva or serum coating on adherence of Streptococcus oralis strains to titanium. Microbiology 2012, 158:390-397.

15. Wright CJ, Burns LH, Jack AA, Back CR, Dutton LC, Nobbs AH, Lamont RJ, Jenkinson HF: Microbial interactions in building of communities. Mol Oral Microbiol 2013, 28:83-101.

16. Lo AW, Seers CA, Boyce JD, Dashper SG, Slakeski N, Lissel JP, Reynolds EC: Comparative transcriptomic analysis of Porphyromonas gingivalis biofilm and planktonic cells. BMC Microbiol 2009, 29:9-18.

17. Welin J, Wilkins JC, Beighton D, Svensater G: Protein expression by Streptococcus mutans during initial stage of biofilm formation. Appl Environ Microbiol 2004, 70:3736-3741.

18. Wickström C, Svensäter G: Salivary gel-forming mucin MUC5B - a nutrient for dental plaque bacteria. Oral Microbiol Immunol 2008, 23:177-182. 
19. Davies JR, Svensäter G, Herzberg MC: Identification of novel LPXTG-linked surface proteins from Streptococcus gordonii. Microbiol 2009, 155:1977-1988.

20. Chavez de Paz LE: Image analysis software based on color segmentation for characterization of viability and physiological activity of biofilms. Appl Environ Microbiol 2009, 75:1734-1739.

21. Kindblom C, Davies JR, Herzberg MC, Svensäter G, Wickström C: Salivary proteins promote proteolytic activity in Streptococcus mitis biovar 2 and Streptococcus mutans. Mol Oral Microbiol 2012, 27:362-372.

22. Ghafouri B, Tagesson C, Lindahl M: Mapping of proteins in human saliva using two-dimensional gel electrophoresis and peptide mass fingerprinting. Proteomics 2003, 3:1003-1015.

23. Schenkels LC, Schaller J, Walgreen-Weterings E, Schadee-Eestermans IL, Veerman EC, Nieuw Amerongen AV: Identity of human extra parotid glycoprotein (EP-GP) with secretory actin binding protein (SABP) and its biological properties. Biol Chem Hoppe Seyler 1994, 375:609-615.

24. Lee B, Bowden GHW, Myal Y: Identification of mouse submaxillary gland protein in mouse saliva and its binding to mouse oral bacteria. Arch Oral Biol 2002, 47:327-332.

25. Schenkels LC, Rathman WM, Veerman EC, Nieuw Amerongen AV: Detection of proteins related to a salivary glycoprotein (EP-GP). Concentrations in human secretions (saliva, sweat, tears, nasal mucus, cerumen, seminal plasma). Biol Chem Hoppe Seyler 1991, 372:325-329.

26. Rathman WM, Van Zeyl MJ, Van den Keybus PA, Bank RA, Veerman EC, Nieuw Amerongen AV: Isolation and characterization of three non-mucinous human salivary proteins with affinity for hydroxyapatite. J Biol Buccale 1989, 17:199-208.

27. Nobbs AH, Lamont RJ, Jenkinson HF: Streptococcus adherence and colonization. Microbiol Mol Biol Rev 2009, 73:407-450.

28. Rodriguez GG, Phipps D, Ishiguro K, Ridgway HF: Use of a fluorescent redox probe for direct visualization of actively respiring bacteria. Appl Environ Microbiol 1992, 58:1801-1808.

29. McDowell SG, An YH, Draughn RA, Friedman RJ: Application of a fluorescent redox dye for enumeration of metabolically active bacteria on albumin-coated titanium surfaces. Lett Appl Microbiol 1995, 21:1-4.

30. Koebmann BJ, Westerhoff HV, Snoep JL, Nillson D, Jensen PR: The Glycolytic Flux in Escherichia coli Is Controlled by the Demand for ATP. J Bacteriol 2002, 184:3909-3916.

doi:10.1186/1472-6831-13-32

Cite this article as: Dorkhan et al: Salivary pellicles on titanium and their effect on metabolic activity in Streptococcus oralis. BMC Oral Health 2013 13:32

\section{Submit your next manuscript to BioMed Central and take full advantage of:}

- Convenient online submission

- Thorough peer review

- No space constraints or color figure charges

- Immediate publication on acceptance

- Inclusion in PubMed, CAS, Scopus and Google Scholar

- Research which is freely available for redistribution 